\title{
Current concepts and principles in open tibial fractures - part i historical background and classification system
}

\begin{abstract}
Throughout history, there has been a fear of open tibial fractures due to the high incidence of infection potentially leading to amputation and death. Before the development of standardized surgical wound treatment and antisepsis, amputations were frequently required to prevent spread of sepsis and risk of death. Even today, this remains a challenging condition to treat. In recent years efforts have been made to develop new techniques and to promote new evidence based guidelines for the management of these injuries. The cooperation between orthopaedic and plastic surgeons together with the use of modern surgical instruments and techniques and modern wound management has resulted in a dramatic reduction in infection rates in many parts of the developed and developing world.
\end{abstract}

Keywords: Review, Open Fracture, Management, Tibia, Historical Background, Classification
Volume 8 Issue 2 - 2017

\author{
Fabian L Poletti,' Simon Macmull, ${ }^{2}$ Nadeem \\ Mushtaq, ${ }^{2}$ Reza Mobasheri \\ 'Dorset County Hospital Foundations Trust, UK \\ ${ }^{2}$ Imperial College Healthcare NHS Trust, UK
}

Correspondence: Fabian Poletti MD, MSc, Orthopaedics and Trauma Surgery, Dorset County Hospital NHS Foundation Trust, UK Email fabypoletti@hotmail.com

Received: March 17,2017| Published: April 24, 2017

\section{Introduction}

Open tibial fractures are challenging injuries to treat. There has been a fear of open tibial fractures due to the increased propensity of infection that has the potential of resulting in amputation or even death. Prior to the advancement of standardized surgical wound treatment and antisepsis and antibiotics, amputations were often a mainstay in the prevention of overwhelming sepsis and ultimately death. Even today, this remains a challenging condition to treat.

Recently efforts have been made to develop new techniques and to promote evidence based guidelines for the management of these injuries. The co-operation between orthopaedic and plastic surgeons together with the use of modern surgical techniques and wound management has resulted in a reduction in infection rates.

\section{Historical perspective}

Ancient Egyptians recognized mandatory coverage of the bone in an open fracture. "Whenever there is a gaping wound, such as that inflicted by the mouth of a crocodile it should be covered with meat" (Edwin Smith Papyrus, Egypt, 1800 BC) (Figure 1). ${ }^{1}$ In 400 $\mathrm{BC}$, amputation was the treatment of choice. Hippocrates said that "not to reduce an open fracture is to incur the reproach of ignorance; to reduce it is to increase the chance of death" (Figure 2). ${ }^{2} \mathrm{He}$ recommended wound lavage with wine solutions and unguents before the application of special bandages. ${ }^{2}$

In ancient China, the treatment of fractures, dislocations and deformities was described by a number of authors since the Tang Dynasty (618-907AD)., "Xian Shou Li Shang Xu Duan Mi Fang" (Secrets of Treating Wounds and Rejoining Fractures Handed Down by a Fairy), written in $846 \mathrm{AD}$ by the Taoist priest Lin of the Tang dynasty is the earliest existing monograph on Orthopaedics and Traumatology in China (Figure 3). For open fractures, Lin advised that the wound first needs to be enlarged with a sharp knife, then washed with boiled water and finally the fracture be reduced by an operation. The wound can then be sutured or not depending on the situation. After suturing, the opening should be wrapped in thin, tough sterile silk. Finally external and internal medication then can be provided. ${ }^{3,4}$

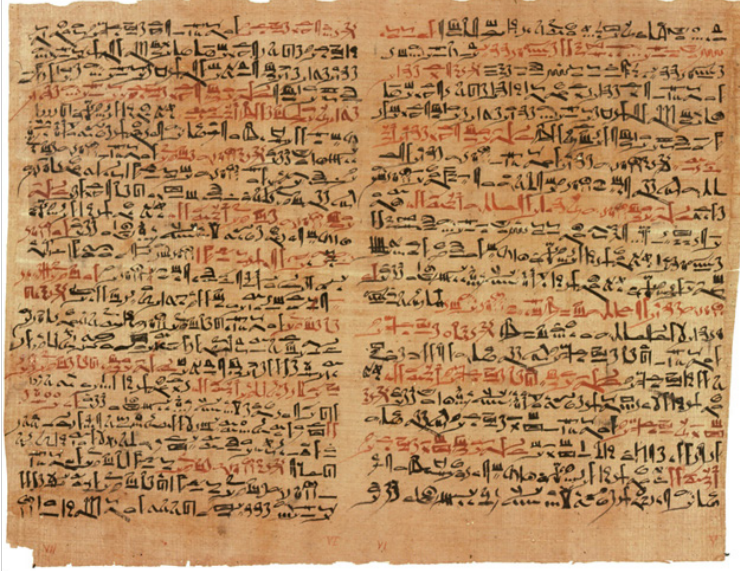

Figure I The Edwin Smith papyrus, the world's oldest surviving surgical document. Manuscript written in hieratic script in ancient Egypt around 1600 B.C. Photographic reproduction of a public domain work of art. (Public Domain).

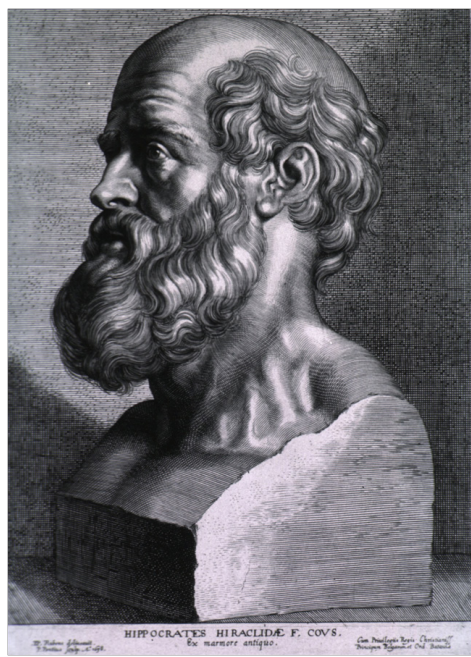

Figure 2 Hippocrates: engraving by Peter Paul Rubens, I638. (Public Domain). 


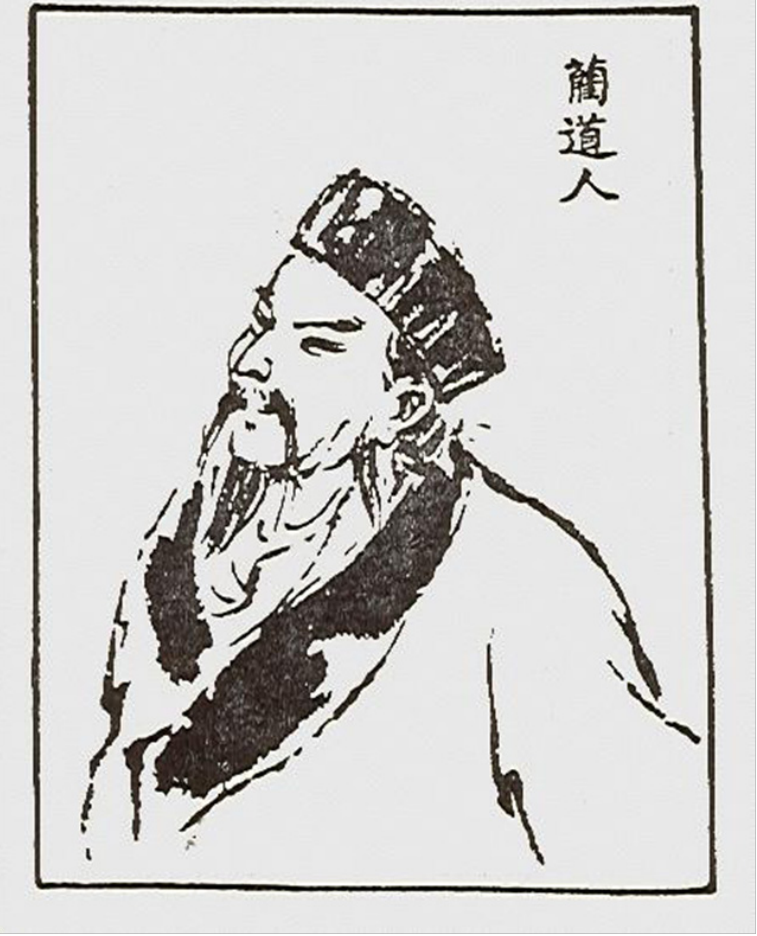

Figure 3 Lin Toist Priest author of the earliest extant monograph on orthopedics and traumatology in China 846 A.D. (Public Domain).

Galeno (129-199 A.D.) better known as Galen of Pergamon, a prominent Greek physician of the Roman Empire, continued with the principles of the Hippocratic school in his way of treating open fractures. ${ }^{5}$ Other physicians of the middle ages such as Paul d'Egine followed Galeno's recommendation for treating open fractures. ${ }^{6}$

Ibn Sina, often known by his last name in Latin Avicenna, in his "Canon of Medicine - Al-qanun fi al-tibb (1020 - 1025 A.D.)" gave priority to treat the wounds in open fractures, advising open drainage for the wounds even if malunion ensues, because of the fear of infection and limb loss (Figure 4). ${ }^{7}$ He stated that "the wounds should have proper cleaning and one should not attempt to close the wound edges until the inflammation subsides. If the wound has a small opening and inflammatory substances accumulate, drainage of the wounds by enlarging the opening is recommended. The nerves should not be exposed along their course and the exposed nerves should be covered by muscles. ${ }^{7}$

In 1545 during the Renaissance, and after treating numerous open fractures inflicted during war, the young French Surgeon Amboise Pare' (Figure 5) summarized the following recommendations: "The skin must forthwith be enlarged so that there may be free passage for both pus or matter, as also for other things the wound may contain and it will be easier to place the bones back to their natural position. If there be any strange bodies, as pieces of wood, iron, bones, bruised flesh, congealed blood, or the like, whether they come from without or within the body. He went on to describe carefully exploring the wound with his digitally rather than the use of surgical instruments to remove any foreign material and loose bits of bone. Pare noted the increased risk of non-union and the risk of infection if devitalized bone was not appropriately debrided. ${ }^{2}$ By turn of fate, some years later in 1561 , he was injured by a horse. His open fracture was treated using his own principles by a colleague. ${ }^{2}$

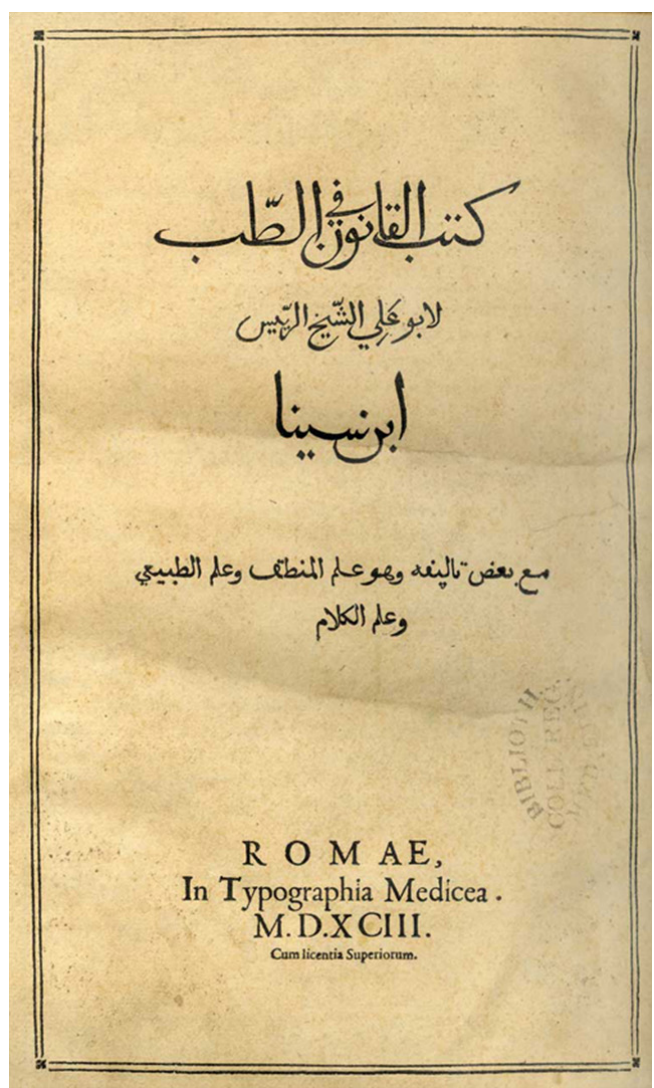

Figure 4 Avicenna's Canon of Medicine - Al-qanun fi al-tibb. The oldest copies of the second volume of "Canon Of Medicine" (1030) by Abu Ali Ibn Sina, known in the West as Avicenna (980-1037). The Institute of Manuscripts of Azerbaijan National Academy of Sciences (Public Domain).

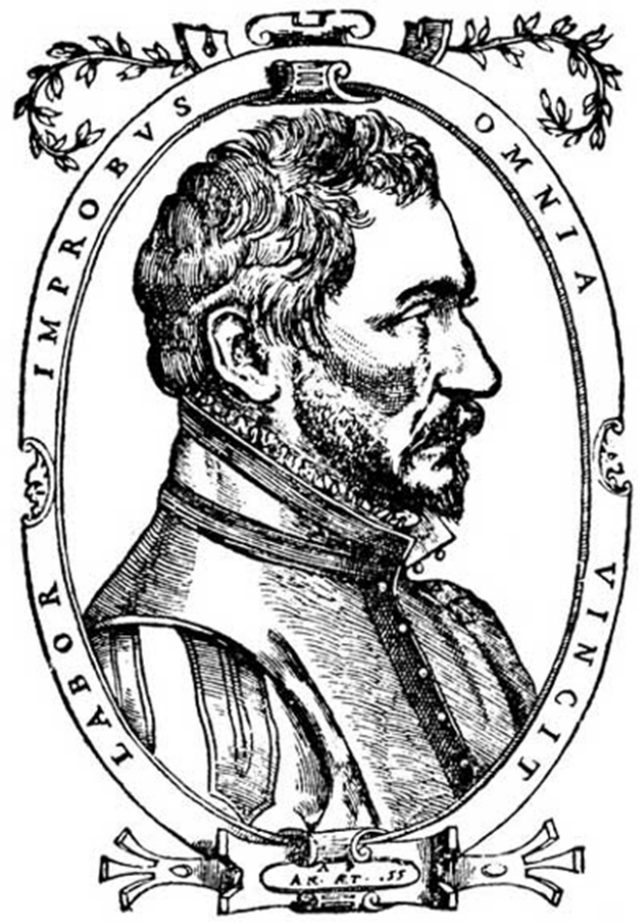

Figure 5 Ambroise Pare:Ambroise Paré aged 55, from:A. Paré:'Deux livres de chirurgie, de la génération de l'homme, \& manière d'extraire les enfans hors du ventre de la mère,... «. Paris: chez André Wechel, 1573 (Public Domain). 
The much revered Sir Percival Pott (Figure 6), also fell off his horse in sustaining an open fracture of the tibia. . ${ }^{2}$ Following discussion with several surgeons and Pott himself it was felt that amputation would be the best course of treatment for his injuries. One of Pott's former apprentices William Nourse intervened who dressed and immobilized the leg with a satisfactory result saving his former mentor's leg. ${ }^{2}$

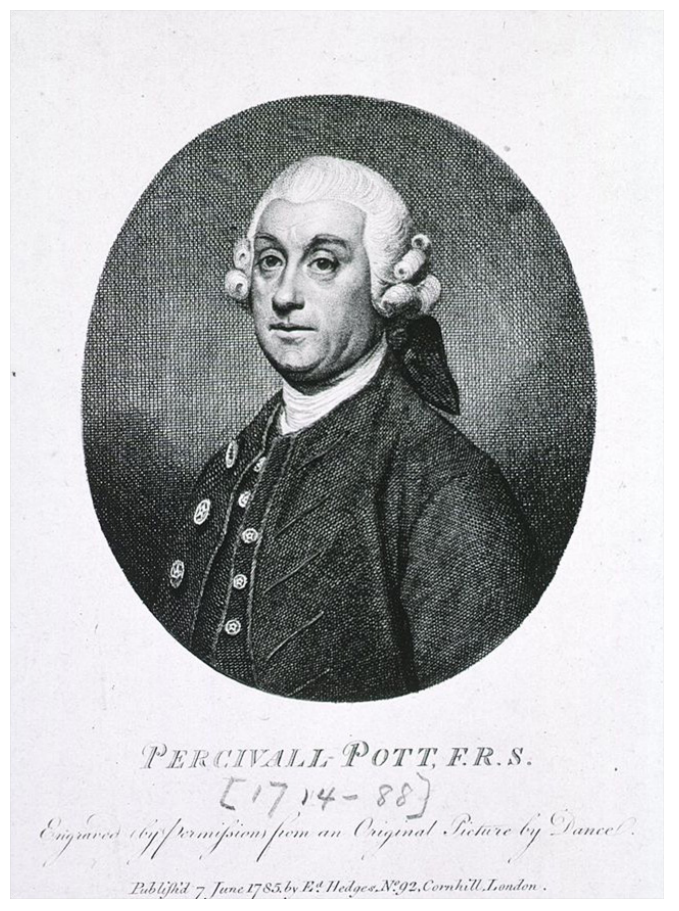

Figure 6 Sir Percivall Pott (6 January 17/4 - 22 December 1788) born in London, England was an English surgeon, one of the founders of Orthopaedics Surgery, and the first scientist to demonstrate that a cancer may be caused by an environmental carcinogen. Portrait, engraved from an original picture by Nathaniel Dance-Holland. (I8th century) - Published by Edward Hedges, London, 1785. National Library of Medicine. (Public Domain).

Battlefield surgery has always proven to be a major reason why there has been advancement in trauma management. Baron Larrey, one of the Napoleonic surgeons, developed special teams to collect the wounded soldiers and rapidly transport them to the nearest field hospitals (Figure 7). ${ }^{2}$ The concept of debridement was termed around this time. Literally meaning the unbridling of a horse. The word is now synonymous with the removal of debris and wound management in the form of extending the wound to adequately explore the wound, allowing free drainage from the wound and the removal of all necrotic tissue. ${ }^{2}$ Since its description, we now know that thorough and accurate debridement is the single most important treatment of open fractures.

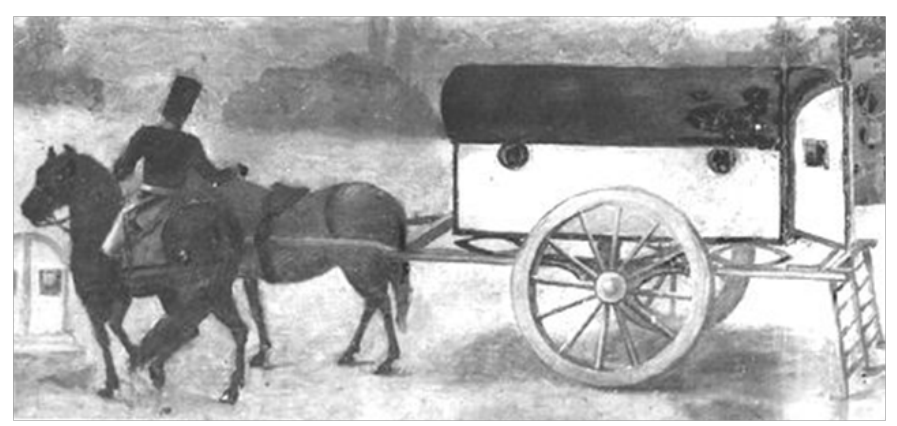

Figure 7 Ambulance Volante or "flying ambulances" to evacuate casualties from the battlefield. Larrey's Flying Ambulance. Author Unknown - The National Library of Medicine. (Public Domain).
The American Civil War with its advancement in ballistics with the introduction of bullets rather than pellets resulted in more open fractures. These new bullets resulted in greater accuracy and range of the firearms of the time. Gunshot wounds were in abundance and as a result open fractures seen were often severe. Because of the severity of the injuries with the new type of weapon, amputation was very common and and a quarter of those injured did not survive their injuries. $^{2}$

The French Surgeon Alexis Carrell was conscripted into the French Army during World War I as a field surgeon. ${ }^{2}$ He had wanted an antiseptic solution that he could use on open wounds. With the help of the chemist Dakin they developed a solution of boric acid and sodium hypochlorite. This solution was used on the open injuries following thorough debridement. Regular wound cultures and bacterial counts were made. Once wound cultures were deemed clear of infection the wound were considered for delayed primary closure. ${ }^{2}$ Because of the overwhelming success of Carrell's technique the U.S. Army adopted it. ${ }^{2}$ The Carrell-Dakin method was not universally popular. Sir Almroth E. Wright (Figure 8) and his Fellow Alexander Fleming, disagreed and carried out a series of their own tests and concluded: "I have not come across any satisfactory clinical or bacteriologic evidence of the utility of antiseptics as employed in infected wounds. The antiseptic treatment of infected wounds is of quite doubtful utility. Frequently infected wounds had to be amputated because antiseptics didn't work." Wright advocated laying the wound open and allowing free drainage of the wound. He went on to say that the wounds should be washed out, the extremity should be splinted and once infection was controlled consider secondary suture closure of the wound. ${ }^{2}$

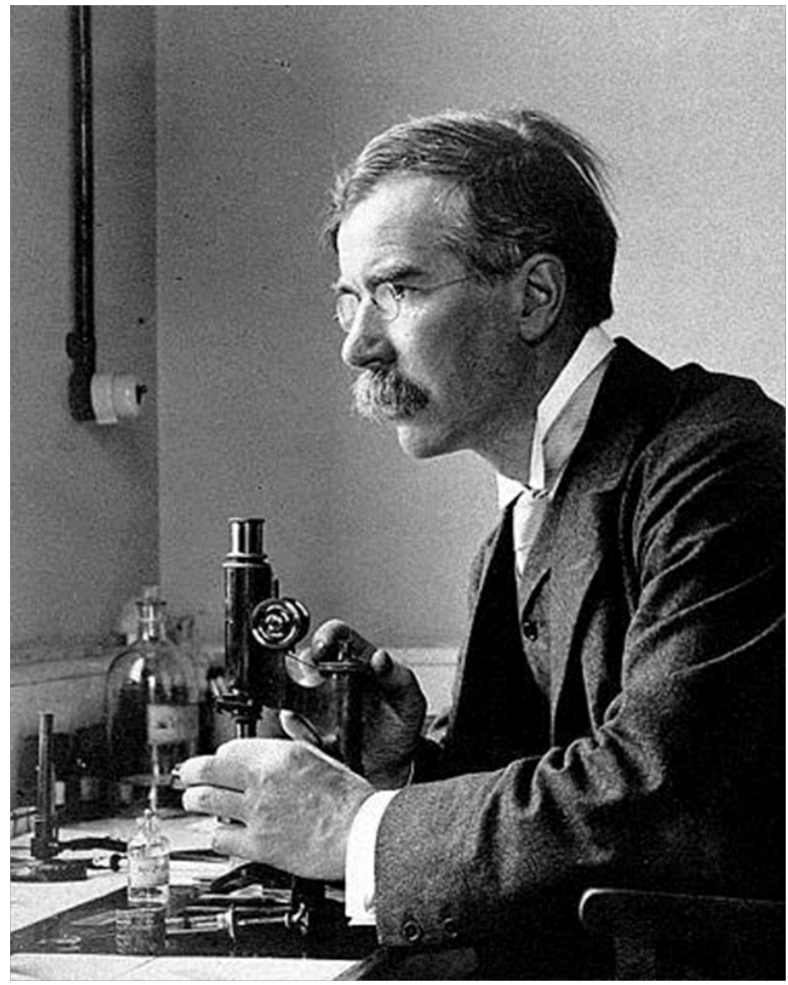

Figure 8 Sir Almroth Edward Wright, (I0 August I86I - 30 April 1947) was a British bacteriologist and immunologist notable for developing a system of anti-typhoid fever inoculation, recognizing early on that antibiotics would create resistant bacteria and being a strong advocate for preventive medicine. Source: Almroth Wright at microscope. 1900. Author unknown. Wellcome Library, London. Copyrighted work available under Creative Commons Attribution only licence CC BY 4.0. 
Dr. Winnett Orr was the biggest critic of Carrell and Dakin's work. He was an American Orthopaedic surgeon who worked in the Army medical Corp. ${ }^{2} \mathrm{He}$ shared a common ground with Carrell regarding thorough debridement of the wound, however he believed it better to pack the open wounds and provide immobilization of the injured limb for an extended period of time. Winnett Orr went on to use this method to great effect in the treatment of chronic osteomyelitis. ${ }^{2}$ During the Spanish Civil War Trueta incorporated Dr Orr methodology of open wound management to great effect. He treated over 1000 cases of open fractures. Casts were changed because of the issues of smell on bimonthly or monthly basis depending on the ambient temperature. Only 4 cases resulted in limb amputation. The only absolute indications for removal of the cast were swelling, uncontrolled pain and an inability to move the end organ (finger and toes). ${ }^{2}$ Although not named, this may be what we describe today as compartment syndrome.

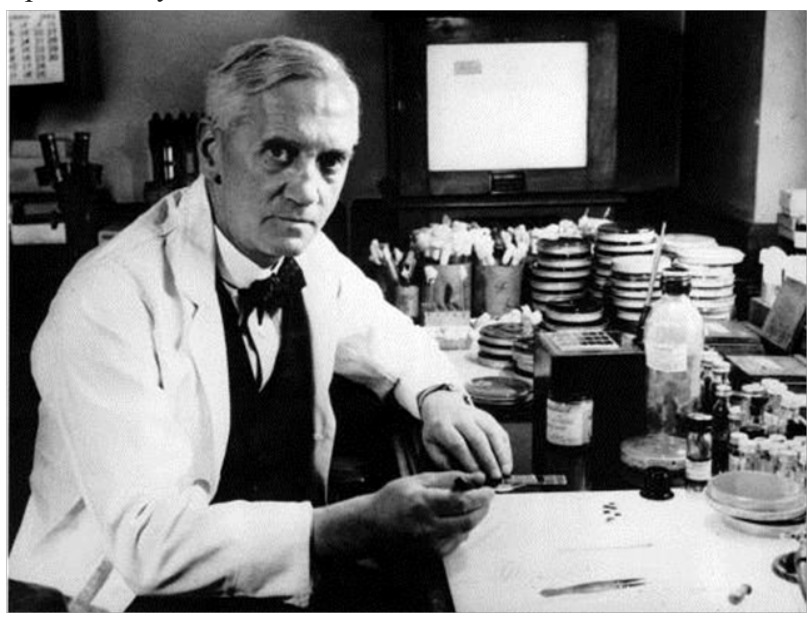

Figure 9 Sir Alexander Fleming. The discovery of penicillin is attributed to Scottish scientist and Nobel laureate Alexander Fleming in 1928. He showed that, if Penicillium rubens were grown in the appropriate substrate, it would exude a substance with antibiotic properties, which he dubbed penicillin. This observation began the modern era of antibiotic discovery. (Public domain).

More recently the use of external fixation has become standard in the management of open fractures, These 'frames' have gone on to provide excellent stability in the face of the more severely comminuted fractures. More recently still, with appropriate soft tissue management. The development of the locked intramedullary nails has proved to be a very useful technique in the stabilization of the open fractures. ${ }^{2}$

\section{Epidemiology}

The frequency of open fractures varies according to population base, geographical and socioeconomic factors. The highest proportion of diaphyseal fractures occur in the tibia $(21.6 \%)$, followed by the femur $(12.1 \%)$, radius and ulna $(9.3 \%)$, and humerus $(5.7 \%){ }^{8}$ This means that tibial fractures represent 1 of every 4 new open fractures, with an incidence of 20/100.000 per year in the United Kingdom .$^{7}$ Almost $60 \%$ of these patients with complex injuries will require reconstructive surgery. ${ }^{8}$

There is a bimodal age distribution with relatively higher younger males and older females. ${ }^{9}$ Grutteret et al. ${ }^{9}$ identified that the majority of fractures occurred in those below 40 years of age, and twice as common in males. ${ }^{9}$

The differentiation of tibial fractures into those of high-energy or low-energy mechanism is important for the associated increase in bone and soft tissue compromise with increasing force of injury. Because of the tibia's poor anteromedial soft tissue coverage, fractures are often open, even from low-energy mechanisms . ${ }^{10}$

\section{Classification}

The classification of open fractures has changed over time. Variable outcomes among different patterns of open fractures with differing severities prompted the development of grading systems that classify based on increasing severity of the associated soft tissue injuries.

\section{The Gustilo andersen classification}

Gustilo and Anderson in 1976 refined Konstantine P. Veliskakis early work with open fracture grading. ${ }^{11}$ Veliskakis treated 80 patients with open fractures in the Derbyshire Royal Infirmary (Derby, England) and published his work in 1959 in New York (U.S.A). ${ }^{12} \mathrm{He}$ divided the fractures in 3 categories depending on the size of the injury and the skin and muscle involvement. ${ }^{12}$ Veliskakis classification was very simple but served as a basis for a more complex classification (Table 1). ${ }^{12}$

Table I Veliskakis Open Fracture Classification

\section{Veliskakis Open Fracture Classification}

Grade I

Puncture wounds from withinor small lacerations up to about one inch in length with no loss of skin and minimal muscle damage.

Grade II Larger wounds over an inch in length with contusion of the adjacent skin of variable degree.

Grade III Severe crush injuries with extensive damage to the skin and muscles, especially in the anterior compartment.

Based on the Veliskakis work, Gustilo and Anderson, prospectively followed more than 350 patients and categorized open injuries into the familiar three categories, based on wound size, level of contamination, and osseous injury as follows. ${ }^{1}$

a. Type I: An open fracture with a wound less than $1 \mathrm{~cm}$ long and clean;

b. Type II: An open fracture with a laceration greater than $1 \mathrm{~cm}$ long without extensive soft tissue damage, flaps, or avulsions; and

c. Type III: Either an open segmental fracture, an open fracture with extensive soft tissue damage, or a traumatic amputation.

Special categories in Type III were gunshot injuries, any open fracture caused by a farm injury, and any open fracture with accompanying vascular injury requiring repair. ${ }^{11}$

Type III open fractures proved the most difficult to classify and treat owing to the varied injury patterns, increased morbidity from associated injuries, massive soft tissue damage or loss over the fracture sites, compromised vascularity, wound contamination, and fracture instability. ${ }^{13}$ Infection in Type III open fractures was observed in up to $50 \%$ of cases..$^{14}$ It became evident that the variation in severity, etiology, and prognosis of Type III injuries made a single classification too non-specific. ${ }^{14}$ The relatively high frequency of these injuries made the issue even more pressing. In response, high energy open fractures were further sub-classified by Gustilo et al. to A, B, and $\mathrm{C}$, according to the severity of the soft tissue injury, need for vascular reconstruction, and worsening prognosis (Table 2 ). ${ }^{13}$

Despite its familiarity and common use in the orthoplaedic community, the Gustilo-Anderson classification has left many questions unanswered. ${ }^{14}$ There is often inter-observer disagreement between different surgeons as to which grade is appropriate for a given injury and often intra-observer differences when shown the 
same injury at different times. ${ }^{14}$ The Gustilo-Anderson classification has undergone unofficial modification in common usage over time creating more variability in the assessment. An important category of the Gustilo-Anderson classification (3B) is determined by how the soft tissue wound is treated (the need for flap coverage signifies a $3 \mathrm{~B}$ category), which is problematic since indications for flap coverage have changed over the last 30 years and vary between clinicians. ${ }^{14}$ The introduction of wound vacuum technology has dramatically reduced the frequency of free flap procedures in many situations. ${ }^{14}$ The problems with the Gustilo-Anderson open fracture classification (poor reliability and reproducibility) and changes in open fracture care techniques over the past 30 years, warrant consideration of an updated classification system for open fractures. ${ }^{14}$

Table 2 Grade III Gustilo and Andersen Open Fractures classification

\begin{tabular}{ll}
\hline Gustillo and Andersen Open Fracture Classification \\
Type III open fractures \\
IIIla $\quad \begin{array}{l}\text { Adequate soft tissue coverage of fractured bone despite } \\
\text { extensive soft tissue laceration or flaps } \\
\text { high energy trauma regardless of the size of the wound } \\
\text { Extensive soft tissue injury loss with periosteal stripping } \\
\text { IIIb } \quad \begin{array}{l}\text { and bone exposure usually is associated with massive } \\
\text { contamination }\end{array} \\
\text { IIlc } \quad \text { Fractures associated with arterial injury requiring repair }\end{array}$
\end{tabular}

Horn and Rettig, and then Brumback and Jones, raised many questions about the lack of reliability of the Gustilo-Anderson classification. ${ }^{14}$ This created interest in ways to improve the reliability of the classification by standardising the timing of the actual classification of the open wound to the end of the surgical debridement. ${ }^{14}$ More recently, in a systematic literature review, Papakostidis et al. showed that the Gustilo-Anderson classification had a strong association with certain patient outcomes but noted moderate to poor inter-observer agreement and lack of objectivity and reproducibility over time even among experienced orthopaedic surgeons. ${ }^{14}$

The Classification and Outcomes Committee of the Orthopaedic Trauma Association (OTA) has developed a new classification for open fractures built on the foundation of the Gustilo-Anderson classification with the attempt to overcome some of its shortcomings. ${ }^{15}$ The OTA open fracture classification (OTA-OFC) was developed to provide clinicians with standardized terminology that could be applied to all open fractures independent of fracture location and treatment. As part of the classification design, it is intended that this standardization of terminology will allow clinicians to aggregate data that describe similar open fractures and develop predictions of treatment and outcome. The variables that comprise this classification are: Skin Injury (S), Muscle Injury (M), Arterial Injury (A), Contamination (C), and Bone Loss (B). ${ }^{9}$ Each variable has an increasing rank order of severity from 1 (mild) to 2 (moderate) to 3 (severe) following the scheme reported in Table 3. ${ }^{15}$

These subcategories are designed to be parallel across the 5 categories. ${ }^{15}$ The classification nomenclature focuses on the characteristics of injury. ${ }^{15}$ The development process and validity of the classification has been published.$^{16}$

Compartment syndrome was considered as a potential "add-on" given that its occurrence is often related to injury severity. ${ }^{14}$ However, compartment syndrome is a distinct clinical entity with a complex diagnostic and treatment algorithm, which suggests that it should be considered separately from the open fracture injury. ${ }^{14}$ Neurologic injury was also felt to be a separate issue not directly related to grading open fracture severity. ${ }^{14}$ Periosteal stripping is difficult to

quantify in isolation and was thought to be better assessed through parameters included in the proposed classification system such as myofascial injury and bone loss as well as through the assessment of fracture pattern. ${ }^{15}$ Fracture pattern, with its own complexity of classification, is accounted for by separate classification systems such as the Orthopaedic Trauma Association Comprehensive Fracture Classification System. ${ }^{15}$

\section{Table 3 OTA Open Fractures Classification}

OTA Open Fractures Classification

\section{Skin Laceration with edges that approximate}

I Laceration with edges that do not approximate

3 Laceration associated with extensive degloving

$\begin{array}{ll}\text { Muscle } & \begin{array}{l}\text { None or minor muscle tissue necrosis; some muscle tissue } \\ \text { injury with intact muscle unit function }\end{array} \\ \text { Loss of significant muscle tissue but the involved muscle unit } \\ \text { I } & \begin{array}{l}\text { Exains in longitudinal continuity } \\ \text { continuity, (partial or complete compartment excision, } \\ \text { muscle defect that does not re-approximate) }\end{array} \\ \text { Arterial } & \text { No major vessel disruption } \\ \text { I } & \text { Vessel injury without distal ischemia } \\ 2 & \text { Vessel injury with distal ischemia } \\ 3 & \text { No grossly visible contamination } \\ \text { Contamination } & \text { Surface contamination, visible } \\ \text { I } & \text { Contaminant embedded in bone or deep soft tissues or high } \\ 2 & \text { risk environmental conditions (barnyard, faecal, dirty water, } \\ 3 & \text { etc.) } \\ \text { Bone loose } & \text { None or insignificant bone loss } \\ \text { I } & \text { Bone missing or devascularized bone fragments, but some } \\ 2 & \text { contact between proximal and distal fragments } \\ 3 & \text { Segmental bone loss }\end{array}$

The timing of classification is important for many reasons. ${ }^{16}$ Classifying an open fracture in the emergency room is useful for physician-to-physician communication as well as for deciding management of the initial injury. ${ }^{16}$ Accurately assessing the degree of injury to deep tissues such as muscle, neurovascular structures, and bone is not always possible before operative exploration of the zone of injury. ${ }^{16}$ Classifying the fracture in later phases of treatment is valuable for assessing the evolution of injury characteristics through the treatment period but will not enhance initial injury severity assessment or guide early treatment. As a result, the end of the initial debridement was felt to be the most optimal time to apply the classification. ${ }^{16}$

\section{Acknowledgments}

None.

\section{Conflicts of interest}

None.

\section{References}

1. Pape HC, Webb LX History of open wound and fracture treatment. History of Open Wound and Fracture Treatment. J Orthop Trauman. 2008;22(10 Suppl):S133-S134.

2. James Harkness The History of Management of Open Fractures. Papers Presented to the Innominate Society of Louisville. 2009

3. Xie Peiping History and Development ofTraditional Chinese Medicine. Science Press, China, pp. 1999;144-145.

4. Junqing $\mathrm{H}$ Achievement of Orthopedics and Traumatology in Secrets of Treating Wounds and Rejoining Fractures Handed Down by a Fairy. Journal of Traditional Chinese Medicinal Literature. $2005 ; 2: 21-23$. 
5. Owen H, Wangensteen, Sarah D The Rise of Surgery: From Empiric Craft to Scientific Discipline. University of Minnesota Press, USA, pp. 785. 1978

6. Adams Francis The seven books of Paulus AEgineta: translated from the Greek: with a commentary embracing a complete view of the knowledge possessed by the Greeks, Romans, and Arabians on all subjects connected with medicine and surgery. Printed for the Sydenham Society. Sydenham Society, London, United Kingdom. 1844

7. Afshar A Concepts of Orthopaedic Disorders in Avicenna's Canon of Medicine. Arch Iran Med 2011;14(2):157-159.

8. O’Brien PJ, Mosheiff R Open fractures. In: Ruedi TP, et al. (Eds.), AO principles of fracture management. Thieme, Germany, pp. 2007;349-369.

9. Court-Brown CM, Brewster N Epidemiology of open fractures. In Court-Brown CM, et al. (Eds.), Management of open fractures. (1st edn), CRC Press, London, UK, p. 1996;25-35.

10. Sharr PJ, Buckley RE Current concepts review: open tibial fractures Acta Chir Orthop Traumatol Cech. 2014;81(2):95-107.
11. Gustilo RB, Anderson JT Prevention of infection in the treatment of one thousand and twenty-five open fractures of long bones: retrospective and prospective analyses. J Bone Joint Surg. 1976;58(4):453-458.

12. Veliskakis KP Primary internal fixation in open fractures of the tibia shaft; the problem of wound healing. J Bone Joint Surg Br. 1959;41B(2):342-354.

13. Gustilo RN, Mendoza RM, Williams DN Problems in the management of type III (severe) open fractures: a new classification of type III open fractures. J Traum. 1984;24(8):742-746.

14. Roberts CS, Adams EL The classification of open fractures. Are we there yet? Injury. 2003;44(4):403-405.

15. Orthopaedic Trauma Association: Open Fracture Study Group A new classification scheme for open fractures. J Orthop Trauma. 2010;24(8):457-465.

16. Agel J, Rockwood T; Barber R et al. Potential Predictive Ability of the Orthopaedic Trauma Association Open Fracture Classification. J Orthop Trauma. 2014;28(5):300-306. 